\title{
The magnitude and factors associated with delays in management of smear positive tuberculosis in Dar es Salaam, Tanzania
} Sayoki G Mfinanga1, Beatrice K Mutayoba*1, Amos Kahwa1, Godfather Kimaro ${ }^{1}$, Rugola Mtandu${ }^{1}$, Esther Ngadaya ${ }^{1}$, Said Egwaga ${ }^{2}$ and Andrew Y Kitua ${ }^{3}$

Address: ${ }^{1}$ NIMR, Muhimbili Medical Research Centre, P.O. Box 3436, Dar es Salaam, United Republic of Tanzania, ${ }^{2}$ National Tuberculosis and Leprosy Programme, Tuberculosis and Leprosy Central Unit, Ministry of Health, P.O. Box 9083, Dar Es Salaam, United Republic of Tanzania and ${ }^{3}$ National Institute for Medical Research, Headquarters, P. O. Box 9653, Dar es Salaam, United Republic of Tanzania

Email: Sayoki G Mfinanga - gsmfinanga@yahoo.com; Beatrice K Mutayoba* - beatricemutayoba@yahoo.com; Amos Kahwa - akahwa@hotmail.com; Godfather Kimaro - fatherdk2002@yahoo.com; Rugola Mtandu - rugorugo@yahoo.com; Esther Ngadaya - engadaya@yahoo.com; Said Egwaga - tantci@intafrica.com; Andrew Y Kitua - akitua@hotmail.com

* Corresponding author

Published: 27 July 2008

BMC Health Services Research 2008, 8:158 doi:10.1186/1472-6963-8-158

This article is available from: http://www.biomedcentral.com/1472-6963/8/158

(c) 2008 Mfinanga et al; licensee BioMed Central Ltd.

This is an Open Access article distributed under the terms of the Creative Commons Attribution License (http://creativecommons.org/licenses/by/2.0), which permits unrestricted use, distribution, and reproduction in any medium, provided the original work is properly cited.
Received: 7 February 2008

Accepted: 27 July 2008

\begin{abstract}
Objective: To assess the magnitude and factors responsible for delay in TB management.

Design: A cross sectional hospital based survey in Dar es Salaam region, May 2006.

Results: We interviewed 639 TB patients. A total of $78.4 \%$ of patients had good knowledge on TB transmission. Only $35.9 \%$ had good knowledge on the symptoms. Patient delay was observed in $35.1 \%$ of the patients, with significantly $\left(X^{2}=5.49\right.$, d.f. $\left.=I, P=0.019\right)$ high proportion in females $(41.0 \%)$ than in males (3I.5\%). Diagnosis delay was observed in $52.9 \%$ of the patients, with significantly $\left(X^{2}=10.1\right.$, d.f. $\left.=I, P=0.00 I\right)$ high proportion in females $(62.1 \%)$ than in males $(47.0 \%)$. Treatment delay was observed in $34.4 \%$ of patients with no significant differences among males and females. Several risk factors were significantly associated with patient's delays in females but not in males. The factors included not recognizing the following as TB symptoms: night sweat (OR $=1.92$, $95 \% \mathrm{Cl}$ I.20, 3.05), chest pain (OR = I.62,95\% Cl I.I, 2.37), weight loss (OR $=1.55,95 \% \mathrm{Cl} I .03$, $2.32)$, and coughing blood $(O R=1.47,95 \% \mathrm{Cl} \mathrm{I.0I}, 2.16)$. Other factors included: living more than

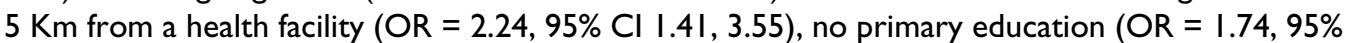
$\mathrm{Cl} \mathrm{I.0I,} \mathrm{3.05)} \mathrm{and} \mathrm{no} \mathrm{employment} \mathrm{(OR} \mathrm{=} \mathrm{I.77,} \mathrm{95 \%} \mathrm{Cl} \mathrm{I.20,} \mathrm{2.60).} \mathrm{In} \mathrm{multiple} \mathrm{logistic} \mathrm{regression,}$ five factors were more significant in females $(\mathrm{OR}=2.22,95 \% \mathrm{Cl} \mathrm{I} .14,4.3 \mathrm{I})$ than in males $(\mathrm{OR}=$ $0.70,95 \% \mathrm{Cl} 0.44, \mathrm{I} . \mathrm{II})$. These factors included not knowing that night sweat and chest pain are TB symptoms, a belief that TB is always associated with HIV infection, no employment and living far from a health facility.
\end{abstract}

Conclusion: There were significant delays in the management of TB patients which were contributed by both patients and health facilities. However, delays in most of patients were due to delay of diagnosis and treatment in health facilities. The delays at all levels were more common in females than males. This indicates the need for education targeting health seeking behaviour and improvement in health system. 


\section{Background}

Tanzania is among countries with the highest TB burden which places it among the twenty two high burden countries. Records from National Tuberculosis and Leprosy Program (NTLP) show that, since 1983 the number of TB cases has increased almost six fold from 11,753 to 65,665 in 2004[1]. The majority of cases appear in young adult population groups aged 15-45 years, the same age group affected by HIV/AIDS. The high rates of HIV infection have had a direct impact on the increase in TB infection rate. HIV prevalence among TB patients is estimated to be $51 \%$ [2-4]. The current TB prevalence is 496 per 100000 population. The estimated annual tuberculosis incidence is 342 per 100,000 of which 147 per 100,000 are smear positive cases [5]. This incidence is highly contributed by a few urban regions with higher population densities and HIV burden. In the year 2004 Dar es Salaam region contributed about $24 \%$ of all cases of tuberculosis $[4,6]$.

The most essential component of tuberculosis control is the early detection and adequate treatment of infectious cases also known as sputum smear positive pulmonary tuberculosis. The primary role of detecting infectious cases is to reduce the transmission of infection in the community. It is estimated that a single infectious person who remains undetected and therefore untreated can infect between ten and fifteen people every year, making a vicious cycle of failing control efforts. The importance of having effective methods of early identification and prompt treatment of these infectious cases within the communities can not be overlooked [7-9].

Delays in both diagnosis and treatment initiation is a major impeding factor in the control of tuberculosis [911]. A study done in Mwanza Tanzania, found that about $80 \%$ of studied patients reported to health facilities longer than thirty days of onset of symptoms, with a mean delay of 162 days. A third of the patients reported as late as six months later [12]. Similarly, studies done in other countries, have shown that, severe underlying illness, poor perceptions of the health services, distance from the clinic and prior attendance to private clinics were the main causes of delays in TB diagnosis [13-15].

Although these studies have shown that delay in management is a composite of factors, some of which relate to the patient while others relate to the health system, factors associated with these delays in Dar es Salaam were unknown. The aim of this study was to assess the magnitude and factors responsible for delay in TB management in Dar es Salaam, Tanzania.

\section{Methods}

A cross sectional hospital based survey was conducted in the three districts of Dar es Salaam region namely Ilala,
Temeke and Mwananyamala in May 2006. Dar es Salaam is a capital city of Tanzania which is located in the eastern central border along the Indian Ocean shore. It has pockets of shanty towns which are densely populated. The region contributes the highest burden of tuberculosis cases in the country.

\section{Selection of DOTS centres and TB patients}

In each district a list of government health facilities was obtained and stratified into hospitals, health centres and dispensaries. A health centre is expected to cater for 50,000 people which is approximately the population of one administrative division while a dispensary caters for between 6,000 to 10,000 people and supervises all the village health posts in its ward.

A random selection of one hospital, two health centres and three dispensaries was done to obtain a total of 18 health facilities. In order to ensure representativeness of private facilities, a list of private hospitals and health centres with DOTS clinics was made. From this list three hospitals and one health centre were selected, making a total of 22 health facilities. During the study, one private hospital declined to participate and therefore was replaced by a dispensary. In each DOTS centre investigators interviewed all confirmed smear positive tuberculosis patients who came for treatment and were diagnosed within the past two months before commencement of the study.

We enrolled smear positive acid fast bacilli patients only, which according to the NTLP criteria, were all cases who submitted three sputum specimens, first spot, second morning, and third spot, and where by, at least two of the specimens were positive.

A total of 639 smear positive TB patients were interviewed. An interviewer administered questionnaire which included two parts was used. The first part included patient's particulars, knowledge on TB symptoms, transmission, cure, perception on co-infection with HIV and questions on health seeking behaviour. The second part included record reviews on diagnosis and treatment information extracted from investigation forms, laboratory and treatment registers.

\section{Categories of delays}

The patient's self referral interval was defined as the time interval between the onset of symptoms and the first doctor visit. Intervals that exceeded 30 days were considered as patient delay. The health facility referral interval was defined as the time between the first visit to a doctor at any health facility and the time the patient is seen at a health facility with DOTS services. Intervals that exceeded two days were considered as referral delay. 
The diagnosis interval was regarded as the time between first consultation at a health facility with DOTS services and a time when a definitive diagnosis of tuberculosis is made (based on results of three sputum samples). Intervals that exceeded three days were considered indicative of a diagnosis delayed. The treatment interval was regarded as the interval between time of diagnosis and treatment initiation. Intervals that exceeded one day from a definitive diagnosis were considered as a treatment delay. Facility interval was regarded as time interval from when the patients were first seen at health facility with DOTS and treatment initiation. An interval that exceeded five days was regarded as a facility delay.

These definitions were derived from NTLP guidelines for diagnosis and treatment of TB patients [6]. Patient's delays and referral delays were derived from interviews with consultants involved in policy and management of TB and experience from previous publications.

Patients who knew that TB can be spread from person to person by coughing/sneezing were defined as having 'good' knowledge on the transmission. Patients who selected cough plus two other symptoms (from the following: fever, chest pain, shortness of breath, night sweating, loss of body weight, coughing blood) were defined as having 'good' knowledge of TB symptoms.

\section{Analysis}

The data collected was double entered, cleaned and coded using Epi-info version 6 (Centres for Disease Control and Prevention, Atlanta, GA, USA). Analysis was done using SPSS version 14 for Windows (SPSS Inc, Chicago, IL, USA). Pearson Chi square and Wald statistics tests were used to compare group differences for categorical variables. The variables were adjusted or stratified for sex to control for possible interaction and confounding effect. Adjusted Odds Ratios (OR) with 95\% confidence intervals (CI) is reported. Differences were considered statistically significant if $P \leq 0.05$. Logistic regression was used for modelling multiple risks for patients diagnosis delay. Variables that were considered significant in the univariate analysis were analysed using multivariate analysis. Backward stepwise selection with removal testing was used, which based on probability of the likelihood ratio statistic. The significance level of a likelihood ratio statistic was compared to a cut-off value of 0.1 . Ten variables were considered in the initial model. Only five variables were considered significant based on the $\mathrm{p}$ value for likelihood ratio $(-2$ Log likelihood $=505.4, \mathrm{P}=0.047)$, clinical and epidemiological importance.

Ethics approval to conduct this study was granted by the Medical Research Coordinating Committee at the National Institute for Medical Research. Informed verbal consent was obtained from each individual enrolled into the study.

\section{Results \\ General characteristics}

The general characteristics are shown in Table 1. A total of 639 TB patients were interviewed in this study. Males and females were 60.7\% (388/639) and 39.3\% (251/639) respectively. The mean age in years (SD) was 35.1 (12.1) for males and 33.1(11.2) for females and 71.5\% (454/ $635)$ of the participant were 18 to 40 years old. Most of the study participants $64.2 \%(408 / 639)$ lived within $5 \mathrm{~km}$ to a near by health facility with DOTS services.

\section{General knowledge of TB among patients attending DOTS clinics}

Generally 78.4\% (423/540) of patients interviewed had a good knowledge on transmission of TB. Only $35.9 \%$ (188/524) had good knowledge on the symptoms of TB disease. For instance, only a number of them recognized night sweat $54.8 \%(284 / 518)$, chest pain $30.6 \%(159 /$ $519)$, shortness of breath $27.6 \%$ (143/519), loss of body weight $26.6 \%(138 / 519)$ and coughing up sputum stained with blood $6.7 \%$ (35/519) as TB symptoms. However, most of them were aware of cough $87.5 \%$ (454/519) and fever $74.4 \%(386 / 519)$ as symptoms of TB. In terms of treatment, $97.4 \%(531 / 545)$ of patients interviewed believed that TB can be cured by medicines (Table 2).

\section{Health seeking behaviour}

Table 3 shows the health seeking behaviours of the interviewed patients. More than a third of study participants sought medical advice first at dispensaries 36.7\% (232/ 633), followed by district hospitals 27.5\% (174/633) then health centres $13.6 \%(86 / 633)$ and private facilities $13.4 \%$ (85/633). However there were no significant differences observed in the distribution of the proportions among males and females in seeking medical care in these facilities.

The mean (SD) and median duration of patient's self referral interval was 37.4 (64.3) and 14 days, respectively. The patient's delay was observed to be more than 30 days in $35.1 \%(207 / 589)$ of the patients, with significantly $\left(\mathrm{X}^{2}\right.$ $=5.49$, d.f. $=1, \mathrm{P}=0.019)$ high proportion in females $41.0 \%(93 / 227)$ than in males $31.5 \%$ (114/362).

The referral delay was observed in $89.4 \%(388 / 434)$ of study patients. This delay was significantly $\left(\mathrm{X}^{2}=7.60\right.$, d.f. $=1, \mathrm{P}=0.009)$ higher in females $94.6 \%(157 / 166)$ than in males $86.2 \%(231 / 268)$.

The first sputum collection (spot sputum) was not done on the same day of health facility visit in $64.3 \%(348 /$ 541 ) of the study participants. Moreover, when the first 
Table I: Profile Characteristics of Study Population

\begin{tabular}{|c|c|c|c|}
\hline Profile Characteristics & $\begin{array}{l}\text { Male } \\
\text { n (\%) } \\
388(60.7)\end{array}$ & $\begin{array}{l}\text { Female } \\
\mathrm{n}(\%) \\
25 \mathrm{I}(39.9)\end{array}$ & $\begin{array}{l}\text { Total } \\
\mathrm{N}(\%) \\
639(100.0)\end{array}$ \\
\hline \multicolumn{4}{|l|}{ Type of facility } \\
\hline Dispensary & $150(38.7)$ & $104(4 \mid .4)$ & $254(39.7)$ \\
\hline Health centre & $126(32.5)$ & $68(27.1)$ & $194(30.4)$ \\
\hline Hospital & I I 2 (28.9) & 79 (3I.5) & $191(29.8)$ \\
\hline Total & 388 & 251 & 639 \\
\hline Mean age in years (SD) & $35.1(12.1)$ & $33.1(11.2)$ & $34.3(11.8)$ \\
\hline \multicolumn{4}{|l|}{ Age (years) } \\
\hline$<18$ & $12(3.1)$ & $7(2.8)$ & $19(3.0)$ \\
\hline $18-40$ & $268(69.4)$ & $186(74.7)$ & $454(7 I .5)$ \\
\hline $4 I-75$ & $106(27.5)$ & $56(22.5)$ & $162(25.5)$ \\
\hline Total & 386 & 249 & 635 \\
\hline \multicolumn{4}{|l|}{ Education } \\
\hline None & $35(8.2)$ & $34(13.5)$ & $66(10.2)$ \\
\hline Some primary school & $64(16.5)$ & $33(13.1)$ & $97(15.2)$ \\
\hline Primary School Completed & $225(58.0)$ & $15 \mid(60.2)$ & $376(58.9)$ \\
\hline Some secondary school & $26(6.7)$ & $16(6.4)$ & $42(6.6)$ \\
\hline Secondary School Completed & $32(8.2)$ & $17(6.8)$ & $49(7.7)$ \\
\hline Post-secondary & $9(2.3)$ & 0 & $9(1.4)$ \\
\hline Total & 388 & 251 & 639 \\
\hline \multicolumn{4}{|l|}{ Occupation } \\
\hline Employed & $62(16.0)$ & $19(7.6)$ & $81(12.7)$ \\
\hline Unemployed & $124(32.0)$ & $126(50.2)$ & $250(39.1)$ \\
\hline Businessman & $51(13.1)$ & $25(10.0)$ & $76(11.9)$ \\
\hline Petty Trader & $97(25.0)$ & $51(20.3)$ & $148(23.2)$ \\
\hline Other & 54 (13.9) & $30(12.0)$ & $84(13.1)$ \\
\hline Total & 388 & 251 & 639 \\
\hline \multicolumn{4}{|l|}{ Marital Status } \\
\hline Never Married & $169(43.7)$ & $81(32.4)$ & $250(39.0)$ \\
\hline Married & $185(47.8)$ & $112(44.8)$ & $297(46.6)$ \\
\hline Divorced//Separated & $28(7.2)$ & $29(11.9)$ & $57(8.9)$ \\
\hline Widowed & $5(1.3)$ & $28(11.2)$ & $33(5.2)$ \\
\hline Total & 387 & 250 & 637 \\
\hline \multicolumn{4}{|l|}{ Ownership } \\
\hline Public & $340(62.0)$ & $208(38.0)$ & $548(85.8)$ \\
\hline Private & $48(52.7)$ & $43(47.3)$ & $91(14.2)$ \\
\hline Total & 388 & 251 & 639 \\
\hline \multicolumn{4}{|c|}{ Distance $(\mathrm{Kms})$ from health facility } \\
\hline$<5$ & $254(65.8)$ & $154(61.6)$ & $408(64.2)$ \\
\hline $5-10$ & $85(22.0)$ & $63(25.2)$ & $148(23.3)$ \\
\hline$>10$ & $47(12.2)$ & $33(13.2)$ & $80(12.6)$ \\
\hline Total & 386 & 250 & 636 \\
\hline
\end{tabular}

Some totals do not add up to 639 owing to missing values

sputum was collected beyond the first day, a significantly $\left(\mathrm{X}^{2}=5.11\right.$, d.f. $\left.=1, \mathrm{P}=0.024\right)$ higher proportion in females $43.6 \%(92 / 211)$ was delayed than in males $33.9 \%$ (112/330).
A small proportion $9.7 \%$ (58/597) delayed for more than 1 day to collect the second (morning) sputum sample. Almost half 54.8\% (325/539) of the patients did not submit the third sample (spot) on the same day of the morn- 
Table 2: Knowledge of TB among the TB patients attending DOTS clinics in Dar es Salaam

\begin{tabular}{|c|c|c|c|}
\hline Areas of Knowledge studied & $\begin{array}{l}\text { Male } \\
\text { n/N (\%) }\end{array}$ & $\begin{array}{l}\text { Female } \\
\text { n/N (\%) }\end{array}$ & $\begin{array}{l}\text { Total } \\
\text { n/N (\%) }\end{array}$ \\
\hline \multicolumn{4}{|l|}{ Recognized symptoms of TB } \\
\hline Cough & $273 / 308(88.6)$ & $|8| / 2||(85.8)$ & $454 / 519(87.5)$ \\
\hline Fever & 250/308 (74.7) & $|56 / 2| \mid(73.9)$ & $386 / 519(74.4)$ \\
\hline Chest Pain & $84 / 308(27.3)$ & $75 / 211(35.5)^{*}$ & $159 / 519(30.6)$ \\
\hline Shortness of breath & $78 / 308(25.3)$ & 65/2II(30.8) & $143 / 519(27.6)$ \\
\hline Much sweating at night & $174 / 308(56.5)$ & $110 / 210(52.4)$ & $284 / 518(54.8)$ \\
\hline Loss of Body weight & $83 / 308(26.9)$ & $55 / 21 I(26.1)$ & $138 / 519(26.6)$ \\
\hline Spit blood & $20 / 308(6.5)$ & $15 / 2||(7.1)$ & $35 / 519(6.7)$ \\
\hline Ever heard of TB & $322 / 384(83.9)$ & $209 / 250(83.6)$ & $531 / 634(83.8)$ \\
\hline TB spread: person to person & $308 / 328(93.9)$ & $204 / 213(95.8)$ & $512 / 541(94.6)$ \\
\hline Sharing cups/bowls & $102 / 313(32.6)$ & $66 / 204(32.4)$ & $168 / 517(32.5)$ \\
\hline Shaking hands & $4 / 313(1.3)$ & $4 / 204(2.0)$ & $8 / 517(1.5)$ \\
\hline Sex & $13 / 313(4.2)$ & $5 / 204(2.5)$ & $18 / 517(3.5)$ \\
\hline Can TB be cured & $320 / 330(97.0)$ & $211215 /(98.1)$ & $531 / 545(97.4)$ \\
\hline If have TB does it mean have HIV also & $69 / 316(21.8)$ & $47 / 201(23.4)$ & $116 / 517(22.4)$ \\
\hline
\end{tabular}

$* X^{2}=4.0, D f=I, P=0.45$, and the rest of variables had no statistical significance differences observed between males and females

Table 3: Health Seeking Behaviour for Tuberculosis among the TB patients attending DOTS clinics in Dar es Salaam

\begin{tabular}{|c|c|c|c|}
\hline Areas of Health Seeking Behaviours studied & $\begin{array}{l}\text { Male } \\
\text { n/N (\%) }\end{array}$ & $\begin{array}{l}\text { Female } \\
\text { n/N (\%) }\end{array}$ & Total n/N (\%) \\
\hline \multicolumn{4}{|l|}{ Severity of the disease } \\
\hline Severe disease ${ }^{\dagger}$ & $73 / 376(19.4)$ & $62 / 244(25.4)$ & $135 / 620(21.8)$ \\
\hline \multicolumn{4}{|l|}{ Facilities where health advice were sought } \\
\hline Regional hospital & $4(1.0)$ & $7(2.8)$ & II (I.7) \\
\hline District hospital & $10 \mathrm{I}(26.2)$ & $73(29.4)$ & $174(27.5)$ \\
\hline Mission hospital & $9(2.3)$ & $6(2.4)$ & $15(2.4)$ \\
\hline Health centre & $60(15.6)$ & $26(10.5)$ & $86(13.6)$ \\
\hline Dispensary & $138(35.8)$ & $94(37.9)$ & $232(36.7)$ \\
\hline Private practitioner & $48(12.5)$ & $37(14.9)$ & $85(13.4)$ \\
\hline Traditional healer & $\mathrm{I}(0.3)$ & $2(0.8)$ & $3(0.5)$ \\
\hline Pharmacy & $21(5.5)$ & $3(1.2)$ & $24(3.8)$ \\
\hline Other & $3(0.8)$ & $0(0)$ & $3(0.5)$ \\
\hline Total & 385 & 248 & 633 \\
\hline \multicolumn{4}{|l|}{ Delays } \\
\hline Patient delay, $>30$ days & $1 \mid 4 / 362(3 \mid .5)$ & $93 / 227(41.0)$ & $207 / 589(35.1)^{*}$ \\
\hline Referral delay $>2$ days & $231 / 268(86.2)$ & $157 / 166(94.6)$ & $388 / 434(89.4)^{* *}$ \\
\hline Diagnostic delay $>3$ days & $131 / 279(47.0)$ & $113 / 182(62.1)$ & $244 / 461(52.9)^{* * * *}$ \\
\hline Treatment delay > I day & $125 / 344(36.3)$ & $67 / 216(31.0)$ & $192 / 560(34.3)$ \\
\hline Facility delay $>5$ days & $289 / 362(79.8)$ & 199/224 (88.8) & $488 / 586(83.3)^{* * * * *}$ \\
\hline | ${ }^{\text {st }}$ sputum collection delay $>0$ days & $206 / 330(62.4)$ & $|42 / 2| \mid(67.3)$ & $348 / 54 I(64.3)$ \\
\hline Ist sputum collection delay > I days & $112 / 330(33.9)$ & $92 / 211(43.6)$ & $204 / 54 \mid(37.7)^{* * * * * *}$ \\
\hline $2^{\text {nd }}$ sputum collection delay $>$ I days & $38 / 358(10.6)$ & $20 / 239(8.4)$ & $58 / 597(9.7)$ \\
\hline $3^{\text {rd }}$ sputum collection delay $>0$ days & $186 / 356(52.2)$ & 139/237 (58.6) & $325 / 593(54.8)$ \\
\hline $3^{\text {rd }}$ sputum collection delay $>$ I days & $|5 / 34|(4.2)$ & $9 / 228(3.8)$ & $24 / 569(4.0)$ \\
\hline
\end{tabular}

tSevere disease was patient's perspective of their general conditions at the time of first attendance to a health facility.

*Pearson Chi-Square $\left(x^{2}\right)=5.49$, d.f. $=1, p=0.019$.

**Pearson Chi-Square $\left(x^{2}\right)=7.60$, d.f $=1, p=0.009$

****Pearson Chi-Square $\left(x^{2}\right)=10.12$, d.f $=1 p=0.001$.

***** Pearson Chi-Square $\left(x^{2}\right)=8.06$, D. $f=1, p=0.005$.

****** Pearson Chi-Square $\left(x^{2}\right)=5.1$ I, D.f $=I, p=0.024$. 
ing sample collection, and there were no significant differences among males and females.

The diagnosis delay was observed in $52.9 \%$ (244/461) of the patients. This was observed more in females $62.1 \%$ $(113 / 182)$ than in males $47.0 \%(131 / 279)\left(\mathrm{X}^{2}=10.1\right.$, d.f. $=1, \mathrm{P}=0.001)$.

Treatment delay was observed in 34.3\% (192/560) of study participants. Facility delay was observed in $83.3 \%$ $(488 / 586)$, and this was significantly $\left(\mathrm{X}^{2}=8.06\right.$, d.f. $=1, \mathrm{P}$ $=0.005)$ high in females $88.8 \%(199 / 224)$ than in males $79.8 \%(289 / 362)$.

\section{Single and modelled multiple risk factors for tuberculosis patients delay}

Multivariate analysis on the risk factors for patients delay according to sex is shown in table 4. Several risk factors were higher and significantly associated with patient's delay in females than in males. These factors included: not recognizing the following as symptoms of TB: chest pain $(\mathrm{OR}=1.62,95 \%$ CI $1.11,2.37)$, night sweating $(\mathrm{OR}=$ $1.92,95 \%$ CI 1.20, 3.05), weight loss (OR $=1.55,95 \%$ CI $1.03,2.32)$ and coughing blood $(\mathrm{OR}=1.47,95 \% \mathrm{CI} 1.01$, 2.16).
Apart from poor knowledge of symptoms, other factors among females included: having no primary education $(\mathrm{OR}=1.74,95 \% \mathrm{CI} 1.01,3.05)$ and higher rates of unemployment $(\mathrm{OR}=1.77,95 \%$ CI 1.20, 2.60).

The final model on multiple risks had the following variables: poor knowledge on night sweat, chest pain, having no employment, residing $>5 \mathrm{~km}$ from a nearby health facility with DOTS services and a belief that TB is always associated with HIV infection. The multiple risks for the five risks factors for patient delay was significantly higher in females $(\mathrm{OR}=2.22,95 \% \mathrm{CI} 1.14,4.31)$ than in males $(\mathrm{OR}=0.70,95 \% \mathrm{CI} 0.44,1.11)$.

\section{Discussion}

This study found that a significant number of patients delayed for almost a month in seeking medical advice following symptoms. A similar study done in Mwanza revealed a higher proportion of patients who delay, perhaps because it included facilities in rural areas and therefore more patients had limited access to health facilities and less education as compared to our study. That study did not show gender differences in delay for seeking health care [12]. In our study, the delay was observed more among female patients. This is not unexpected, as it has been reported that case detection among females is comparatively low as compared to males [16]. Although

Table 4: Single and modelled multiple risk factors for tuberculosis patients diagnosis delay

\begin{tabular}{|c|c|c|c|c|c|c|c|c|}
\hline \multirow[b]{3}{*}{ Risk Factors } & \multicolumn{4}{|c|}{ Females $(n=25 I)$} & \multicolumn{4}{|c|}{ Males $(n=388)$} \\
\hline & \multirow[b]{2}{*}{$\begin{array}{l}>30 \\
\text { Days }\end{array}$} & \multicolumn{3}{|c|}{ Patient delay } & \multicolumn{2}{|c|}{ Patient delay } & \multirow[b]{2}{*}{ OR } & \multirow[b]{2}{*}{$95 \% \mathrm{Cl}$} \\
\hline & & $\begin{array}{l}\leq \mathbf{3 0} \\
\text { days }\end{array}$ & OR & $95 \% \mathrm{Cl}$ & $\begin{array}{l}>30 \\
\text { days }\end{array}$ & $\begin{array}{l}\leq 30 \\
\text { days }\end{array}$ & & \\
\hline \multicolumn{9}{|l|}{ Poor Knowledge on TB Symptoms } \\
\hline Chest Pain & $\begin{array}{l}41 / 79 \\
(51.9)\end{array}$ & $\begin{array}{l}79 / 113 \\
(69.9)\end{array}$ & 0.89 & $0.57-1.37$ & $\begin{array}{l}66 / 94 \\
(70.2)\end{array}$ & $\begin{array}{l}139 / 193 \\
(72.0)\end{array}$ & 0.74 & $0.50-1.08$ \\
\hline Night Sweating & $\begin{array}{l}44 / 79 \\
(55.7)\end{array}$ & $\begin{array}{l}46 / 112 \\
(41.1)\end{array}$ & 1.92 & $1.20-3.05$ & $\begin{array}{l}37 / 94 \\
(39.4)\end{array}$ & $\begin{array}{l}85 / 193 \\
(44.0)\end{array}$ & 0.70 & $0.45-1.09$ \\
\hline TB means HIV co-infection & $\begin{array}{l}9 / 72 \\
(12.5)\end{array}$ & $\begin{array}{l}32 / 1111 \\
(28.8)\end{array}$ & 0.48 & $0.22-1.03$ & $\begin{array}{l}19 / 97 \\
(19.6)\end{array}$ & $\begin{array}{l}42 / 196 \\
(21.4)\end{array}$ & 0.79 & $0.44-1.42$ \\
\hline Having Chest Pain last month & $\begin{array}{l}35 / 87 \\
(40.2)\end{array}$ & $\begin{array}{l}37 / 118 \\
(31.4)\end{array}$ & 1.62 & $\begin{array}{l}\text { I.II-2.37 } \\
\text { Text }\end{array}$ & $\begin{array}{l}21 / 103 \\
(20.4)\end{array}$ & $\begin{array}{l}73 / 230 \\
(31.7)\end{array}$ & 0.70 & $0.49-1.00$ \\
\hline Distance $>5$ to a nearby health facility with DOTS & $\begin{array}{l}45 / 93 \\
(48.4)\end{array}$ & $\begin{array}{l}42 / 134 \\
(31.3)\end{array}$ & 2.24 & $1.41-3.55$ & $\begin{array}{l}36 / 114 \\
(31.6)\end{array}$ & $\begin{array}{l}87 / 247 \\
(35.2)\end{array}$ & 0.71 & $0.46-1.09$ \\
\hline No primary education & $\begin{array}{l}26 / 93 \\
(28.0)\end{array}$ & $\begin{array}{l}29 / 134 \\
(21.6)\end{array}$ & 1.74 & $1.01-3.05$ & $\begin{array}{l}39 / 114 \\
(34.2)\end{array}$ & $\begin{array}{l}53 / 248 \\
(21.4)\end{array}$ & $\mathrm{I} .44$ & $0.91-2.26$ \\
\hline Having no employment & $\begin{array}{l}64 / 14 \mid \\
(45.4)\end{array}$ & $\begin{array}{l}29 / 86 \\
(33.7)\end{array}$ & 1.77 & $1.20-2.60$ & $\begin{array}{l}51 / 170 \\
(30.0)\end{array}$ & $\begin{array}{l}63 / 192 \\
(32.8)\end{array}$ & 0.72 & $0.49-1.06$ \\
\hline Poor knowledge on Weight loss & $\begin{array}{l}60 / 79 \\
(75.9)\end{array}$ & $\begin{array}{l}78 / 113 \\
(69.0)\end{array}$ & 1.55 & $1.03-2.32$ & $\begin{array}{l}74 / 94 \\
(78.7)\end{array}$ & $\begin{array}{l}138 / 193 \\
(71.5)\end{array}$ & 0.91 & $0.62-1.32$ \\
\hline Poor Knowledge on coughing Blood & $\begin{array}{l}74 / 79 \\
(93.7)\end{array}$ & $\begin{array}{l}103 / 113 \\
(91.2)\end{array}$ & 1.47 & $1.01-2.16$ & $\begin{array}{l}89 / 94 \\
(94.7)\end{array}$ & $\begin{array}{l}179 / 193 \\
(92.7)\end{array}$ & 0.75 & $0.51-1.09$ \\
\hline Modelled multiple Risks 1 & -- & -- & 2.22 & $|| 4-4.3 \mid$. & -- & -- & 0.70 & $0.44-1.11$ \\
\hline
\end{tabular}

IThe final model had the following variables: poor knowledge on night sweat, chest pain, having no employment, residing $>5 \mathrm{~km}$ from a nearby health facility with DOTS services and a belief that TB is always associated with HIV infection. For the females, the Model Chi-Square I9.6 (d.f. $=5$, $P=0.00 \mathrm{I}$ ), Wald statistic $=5.57, \mathrm{P}=.018$ ). For males, the Model Chi-Square 17.42 (d.f. $=4, P=0.002)$, Wald statistic $=2.22, \mathrm{P}=0.136$ ). Total in female and males do not add up to $25 \mathrm{I}$ and 388 , respectively, due to missing values 
there was a study which suggested that the difference in TB case notification between males and females could be more epidemiological than due to inaccessibility [17], these findings had some limitations and were inconclusive for the African region and could not rule out the role of other factors. Our study revealed that more females who delayed had poor knowledge of TB symptoms, misconceptions in relation to HIV, higher rates of unemployment and limited accessibility, all of which are relevant factors in causing delay in seeking health care. These findings indicate the need to increase tuberculosis awareness among females attending health facilities for other reasons. Ante Natal Clinics, Maternal and Child Health Clinics and Reproductive Health Clinics could be used as entry points for raising awareness.

Apart from gender differences, generally a high proportion of patients had an incomprehensive knowledge of TB symptoms, having a fairly good knowledge on only a few symptoms like cough and fever. This could explain the delay in seeking health care as these may be taken for symptoms of malaria or mild chest infections of which patients usually self medicate until they fail to get well.

Most of the patients were aware that $\mathrm{TB}$ is curable with modern medicines and therefore they would eventually seek medical care at health facilities regardless of delay in making that decision.

Nonetheless, delays within the health system although of shorter duration as compared to patients delay were observed in this study, a finding similar to a previous study in Ethiopia [11]. There was a significant referral delay in more than $80 \%$ of the studied patients. This is somewhat alarming as there is an adequate number of health facilities providing DOTS services in Dar es Salaam. Although there could be interplay of factors between patients and the health facilities, the need for a rigorous referral system to ensure that there is no loss or delay in between health facilities can not be overlooked.

This study revealed a diagnosis delay in more than half of the patients. This was highly contributed by inconsistencies in sputum collection. These were not done in a timely manner whereby in a significant number of patients sputum collection were either not done on the same day of the consultation with subsequent delays in the examinations of the second and third sputum samples, or failure to collect the third spot sputum on the same day as the second morning sputum. Furthermore, there were delays to initiate treatment in about a third of patients, and making approximately a facility delay of $80 \%$. Delay in diagnosis and treatment are a much clearer reflection of weaknesses within the health system as compared to referral delay. Given the fact that TB detection rate in Tanzania is low, considering patient, referral, diagnosis and treatment delay it would appear that most of the patients in Dar es Salaam take long before being diagnosed and treated. It implies that a lot of transmission in the communities takes place before patients are diagnosed and treated. This can be significantly avoided by interventions to increase early case detection in the communities and health facilities. Within the community the interventions should target change of behaviour towards health seeking practices and knowledge of TB symptoms and transmission. Within the health facilities, improving ways of tracking TB suspects could reduce the number of patients who are bound to disappear or fail to adhere to the recommended sputum collection schedules.

The distribution of TB patients in our study has well reflected the distribution of TB services in Dar es Salaam and probably in most of cities in developing countries whereby only a few private facilities offer DOTS services compared to public facilities [18]. In this study only a few patients attended private facilities (14\%). Although, interventions to improve $\mathrm{TB}$ services in public facilities are more likely to benefit a large proportion of TB patients in this setting, recently, there has been an increasing trend of patients attending private facilities [18-20]. The interventions to improve early case detection and treatment should also target $\mathrm{TB}$ service in private facilities. It is important that the interventions should take place as an element of public private partnership.

Delays were more common in females indicating that within our health system there is a need of putting more emphasis on strict follow up measures for female TB suspects and patients.

Patient delays were determined retrospectively hence estimations could have been limited by recall biases, however these findings indicate that there is a significant time that lapses before symptomatic patients seek medical care.

\section{Conclusion}

There were significant delays in the management of TB patients which is contributed by both patients and health facilities. However, delays in most of patients were due to delay of diagnosis and treatment in health facilities. The delays at all levels were more common in females than males. TB symptoms and signs, lack of education and employment, and long distance from health facilities were more associated with female patients delay. These risk factors could be addressed through health education not only for tuberculosis patients but also within the communities. Addressing special ways of improving delivery of health education to vulnerable groups such as women is of paramount importance. Improvement within the health system should stress on the need to improve TB 
suspects follow up from the time of consultation throughout diagnosis and treatment initiation.

\section{Competing interests}

The authors declare there are no competing interests.

\section{Authors' contributions}

GS Provided substantial contribution to the conception, study design, analysis and interpretation of data. Actively involved in the drafting of manuscript and revising it critically. He has given final approval of the version to be published. BM Provided substantial contribution to the conception, study design, acquisition of data, analysis and interpretation of data. Actively involved in the drafting of manuscript and revising it critically. He has given final approval of the version to be published. AK Provided substantial contribution to the conception, study design, acquisition of data, analysis and interpretation of data. Actively involved in the drafting of manuscript and revising it critically. He has given final approval of the version to be published. GK Provided substantial contribution to the conception, study design, acquisition of data, analysis and interpretation of data. Actively involved in the drafting of manuscript and revising it critically. He has given final approval of the version to be published. RM Provided substantial contribution to the conception, study design, acquisition of data, analysis and interpretation of data. Actively involved in the drafting of manuscript and revising it critically. He has given final approval of the version to be published. EN Provided substantial contribution to the conception, study design, acquisition of data, analysis and interpretation of data. Actively involved in the drafting of manuscript and revising it critically. He has given final approval of the version to be published. SE Actively involved in the drafting of manuscript and revising it critically. He has given final approval of the version to be published. AK Actively involved in the drafting of manuscript and revising it critically. He has given final approval of the version to be published.

\section{Acknowledgements}

The authors are grateful to all the health staff of the studied DOTS facilities as well as the patients who agreed to participate in this study. This study received funding from the government of Tanzania.

\section{References}

I. Ministry of Health, Department of Preventive Medicine, National Tuberculosis, and Leprosy Control Program, Tanzania: Annual reports 1979-2004.

2. van Cleeff MR, Chum $\mathrm{H}$ ): The proportion of tuberculosis cases in Tanzania attributable to human immunodeficiency virus. Int J Epidemiol I995, 24(3):637-42.

3. Range N, Ipuge YA, O'Brien RJ, Egwaga SM, Mfinanga SG, Chonde TM, Makadi YD, Borgdoff MW: Trend in HIV prevalence among tuberculosis patients in Tanzania, I991-1998. Int J Tuberc Lung Dis 200I, 5(5):405-12.

4. The United Republic of Tanzania. Health Statistics Abstract: Burden of Disease and Health Facility Utilization Statistics. Ministry of Health; 2002.
5. World Health Organization: Global tuberculosis control: Surveillance, planning and financing. WHO Report Geneva: WHO; 2007.

6. The United Republic of Tanzaniam, Ministry of Health: Manual of the national tuberculosis and leprosy programme in Tanzania. Fifth edition. 2006.

7. Frieden T: Toman's Tuberculosis: Case detection, treatment, and monitoring - questions and answers. Second edition. WHO Geneva; 2004.

8. World Health Organization: Tuberculosis fact sheet. Geneva 2007.

9. Odusanya $O O$, Babafemi JO: Patterns of delays amongst pulmonary tuberculosis patients in Lagos, Nigeria. BMC Public Health 2004, 4: 18.

10. Kiwuwa MS, Charles K, Harriet MK: Patient and health service delay in pulmonary tuberculosis patients attending a referral hospital: a cross-sectional study. BMC Public Health 2005, 5: 122.

II. Demissie M, Lindtjorn B, Berhane $Y$ : Patient and health service delay in the diagnosis of pulmonary tuberculosis in Ethiopia. BMC Public Health 2002, 2:23.

12. Wandwalo ER, Morkve O: Delay in tuberculosis case-finding and treatment in Mwanza, Tanzania. Int J Tuberc Lung Dis 2000, 4(2): $133-8$.

13. Guneyliouglu D, Yilmaz A, Bilgin S, Bayram U, Akkaya E: Factors affecting delays in diagnosis and treatment of pulmonary tuberculosis in a tertiary care hospital in Instanbul, Turkey. Med Sci Monit 2004, I 0(2):CR62-7.

14. Godfrey-Fausset P, Kaunda H, Kamanga J, van Beers S, van Cleeff M, Kumwenda-Phiri R, Tihont V: "Why do patients with cough delay seeking care at Lusaka urban health centres?" A health systems research approach. Int J Tuberc Lung Dis 2002, 6(9):796-805.

15. Ward J, Siskind V, Konstantinos A: Patients and health care system delays in queensland tuberculosis patients (1985-1998). Int J Tuberc Lung Dis 200 I, 5( I I): I02I-7.

16. Diwan VK, Thorson A: Sex, gender and tuberculosis. Lancet 1999, 353(9157): |000-0I.

17. Borgdorff MW, Nagelkerke NJ, Dye C, Nunn P: Gender and tuberculosis: a comparison of prevalence surveys with notification data to explore sex differences in case detection. Int J Tuberc Lung Dis 2000, 4(2): I 23-32.

18. The United Republic of Tanzania, Ministry of Health: Annual report of the National Tuberculosis and Leprosy Programme in Tanzania. 2005.

19. The United Republic of Tanzania, Ministry of Health: Annual report of the National Tuberculosis and Leprosy Programme in Tanzania. 2006.

20. The United Republic of Tanzania, Ministry of Health: Annual report of the National Tuberculosis and Leprosy Programme in Tanzania. 2004.

\section{Pre-publication history}

The pre-publication history for this paper can be accessed here:

http://www.biomedcentral.com/1472-6963/8/158/pre pub 